\title{
Dermatite alérgica à picada de Culicoides em muar: relato de caso
}

\author{
[Allergic dermatitis due to bite of Culicoides in muar: case report] \\ T.I.B. Silva ${ }^{1}$, L.A.K. Melchior ${ }^{1}$, L.C.F. Baptista Filho ${ }^{2}$, A.C.C. Fernandes ${ }^{2}$, L.G. Silva ${ }^{2}$, \\ K.F. Vasconcelos ${ }^{2}$, R.G. Revorêdo ${ }^{2}$, D.D. Silva ${ }^{2}$, L.E.H. Melo ${ }^{2}$ \\ ${ }^{1}$ Universidade Federal do Acre - UFAC - Rio Branco, AC \\ ${ }^{2}$ Universidade Federal Rural de Pernambuco - UFRPE - Recife, PE
}

\section{RESUMO}

A dermatite alérgica à picada de ectoparasitos é uma enfermidade alergoparasitária bastante comum entre animais domésticos, sendo relatada principalmente em pequenos ruminantes e em animais de companhia. Contudo, a doença é pouco diagnosticada na clínica de equídeos devido a similaridades nosológicas com outras dermatopatias. Objetivou-se, com este relato de caso, descrever a síndrome clínica, o plano diagnóstico e a conduta terapêutica de um muar acometido por essa enfermidade. Atendeu-se, no Hospital Veterinário da Universidade Federal Rural do Pernambuco, uma mula de oito anos de idade, que apresentava lesões cutâneas pápulo-crostosas e pruriginosas com evolução clínica de dois anos. Em três situações anteriores, a doença havia sido tratada como dermatite fúngica por outros médicos veterinários. Para o diagnóstico, foram solicitados exame citopatológico e parasitológico de pele, cultivo bacteriológico e fúngico, análise histopatológica e hemograma. Os exames demonstraram uma dermatite superficial perivascular eosinofílica crônica, sendo indicada a terapia tópica com dimetilsufóxido, sulfadiazina, ureia e vitamina A. O protocolo terapêutico mostrou-se satisfatório, permitindo completa remissão do quadro clínico. Este trabalho relatou achados clínicos e patológicos da dermatite alérgica à picada de Culicoides spp. em muar, além de alertar sobre a importância de exames complementares para a realização do diagnóstico diferencial e para o direcionamento terapêutico adequado.

Palavras-chave: dermatopatias, alergia, ectoparasitos, equídeos

\begin{abstract}
Allergic dermatitis to ectoparasite bites is a common parasitic disease among domestic animals, being reported mainly in small ruminants and companion animals. However, the disease is poorly diagnosed in equine clinics due to nosological similarities with other skin diseases. The aim of this case report was to describe the clinical syndrome, the diagnostic plan and the therapeutic management of a mule affected by this disease. An 8-year-old mule was observed at Universidade Federal Rural de Pernambuco, presenting papular-crusted and pruritic cutaneous lesions with clinical evolution of two years. In three previous situations, the disease had been treated as fungal dermatitis by other veterinarians. For the diagnosis, cytopathological and parasitological examination of the skin, bacteriological and fungal culture, histopathological analysis and blood count were performed. The exams showed a chronic eosinophilic perivascular superficial dermatitis. A topical therapy with dimethyl sulfoxide, sulfadiazine, urea, and vitamin A was indicated. The therapeutic protocol was satisfactory, allowing complete remission of the clinical condition. This work reported clinical and pathological findings of allergic dermatitis to the bites of Culicoides spp. in muar, in addition to alerting about the importance of complementary examinations for the accomplishment of the differential diagnosis and adequate therapeutic orientation.
\end{abstract}

Keywords: Dermatopathies, allergy, ectoparasites, equidae

Recebido em 14 de setembro de 2016

Aceito em 6 de janeiro de 2017

E-mail: tamyres.ibs@hotmail.com 


\section{INTRODUÇÃO}

A dermatite alérgica à picada de ectoparasitos (DAPE) é uma enfermidade alergoparasitária bastante comum entre animais domésticos, tendo maior incidência em regiões de clima tropical ou subtropical (Broströn et al., 1987). Embora seja frequentemente observada em pequenos ruminantes e em animais de companhia, a doença também ocorre em outras espécies, não havendo predisposição para idade, sexo ou raça (Ferreira, 2007). Em equídeos, o primeiro registro ocorreu na França, em 1840. No Brasil, a doença já foi relatada nas raças Árabe e Crioulo, em São Paulo e no Rio Grande do Sul, respectivamente (Henry e Bory, 1937; Portugal et al., 1996).

Os principais responsáveis pelo surgimento da DAPE são Anopheles spp., Stomoxys spp., Aedes spp., Simulium spp., Culex spp. e, sobretudo, os Culicoides spp.(Portugal et al., 1996; Hellberg et al., 2006; Corrêa et al., 2007). A deposição de componentes proteicos provenientes da saliva desses artrópodes na pele do hospedeiro durante o repasto sanguíneo estimula a produção de imunoglobulinas E (IgE) por plasmócitos e desencadeia uma resposta imunológica específica (Tizard, 2002).

A manifestação clínica é expressa por uma dermatite crônica, altamente pruriginosa, levando à formação de áreas alopécicas, eritematosas, com lesões pápulo-crostosas ou, até mesmo, ulcerativas, nos casos mais graves, sendo comumente observadas em região periocular, pavilhão auditivo externo, pescoço, linha média do dorso, porção ventral do abdômen, inserção da cauda e dos membros (Fadok e Greiner, 1990; Ferreira, 2007). Dessa forma, os animais acometidos apresentam inquietação acentuada, anorexia, queda de peso e do desempenho físico, grave depreciação do couro e podem vir a óbito por eventuais infecções secundárias (Corrêa et al., 2007).

A identificação da enfermidade é baseada no histórico de exposição a ectoparasitos, distribuição corpórea das lesões, exames complementares e resposta terapêutica, porém muitas vezes o diagnóstico é impreciso, levando a falhas no tratamento (Hellberg et al., 2006).

Neste sentido, objetivou-se, com este relato de caso, descrever a síndrome clínica, o plano diagnóstico e a conduta terapêutica em um muar acometido pela dermatite alérgica à picada de Culicoides.

\section{CASUÍSTICA}

Um muar, fêmea, com oito anos de idade, foi atendido no hospital veterinário da Universidade Federal Rural de Pernambuco, com queixa de lesões cutâneas na região da cernelha. $\mathrm{O}$ animal procedia de um sítio localizado no município de Camaragibe-PE, havendo outros três muares na propriedade, porém assintomáticos.

$\mathrm{Na}$ anamnese, foi relatada dermatopatia com evolução clínica de aproximadamente dois anos, resultando em anorexia, perda de peso e declínio do desempenho físico. Em situações anteriores, a doença havia sido diagnosticada como dermatite fúngica por três médicos veterinários, os quais prescreveram a administração tópica de cetoconazol, sem, contudo, obter-se resposta terapêutica.

Ao exame clínico, notaram-se lesões pápulo-crostosas, hipotricóticas e eritematosas, além de hiperqueratose e hiperpigmentação, principalmente na região cervical dorsal, na linha média dorsal, na região lombar e nos pavilhões auriculares (Fig.1). $\mathrm{O}$ animal se esfregava constantemente nas paredes da baia, o que denotava um prurido intenso, e apresentava magreza.

Para o diagnóstico, foram solicitados exames citopatológico e parasitológico de pele, cultivo bacteriológico em ágar sangue ovino, cultivo fúngico em ágar Saboraund, análise histopatológica de fragmento cutâneo em coloração de hematoxilina-eosina (HE) e hemograma.

O exame citopatológico demonstrou a presença de intensa resposta neutrofílica e macrofágica, além de bactérias cocoides (Fig. 2). No cultivo bacteriológico, houve o crescimento de colônias translúcidas, com cerca de $1 \mathrm{~mm}$ de diâmetro, superfície lisa, brilhante e contorno circular. A microscopia desses isolados apresentou cocos Gram positivos, agrupados, medindo aproximadamente $1 \mu \mathrm{m}$, os quais, associados à caracterização bioquímica, eram compatíveis com Streptococcus spp. O exame parasitológico de pele e o cultivo fúngico foram negativos. 


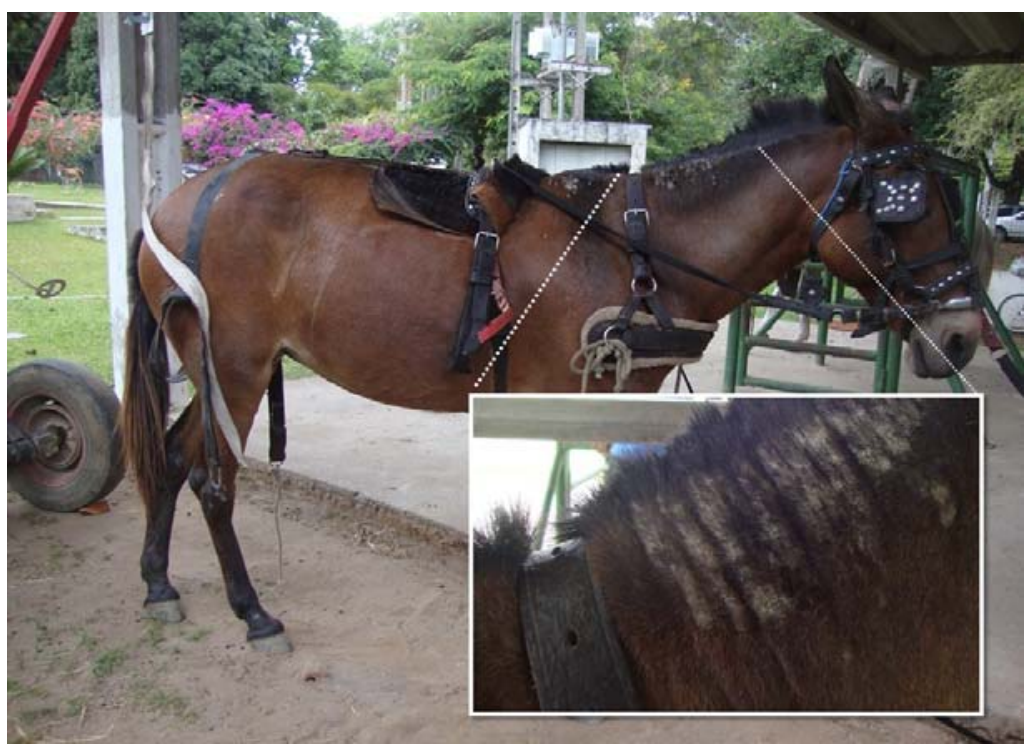

Figura 1. Muar com lesões pápulo-crostosas e alopécicas na região cervical dorsal.

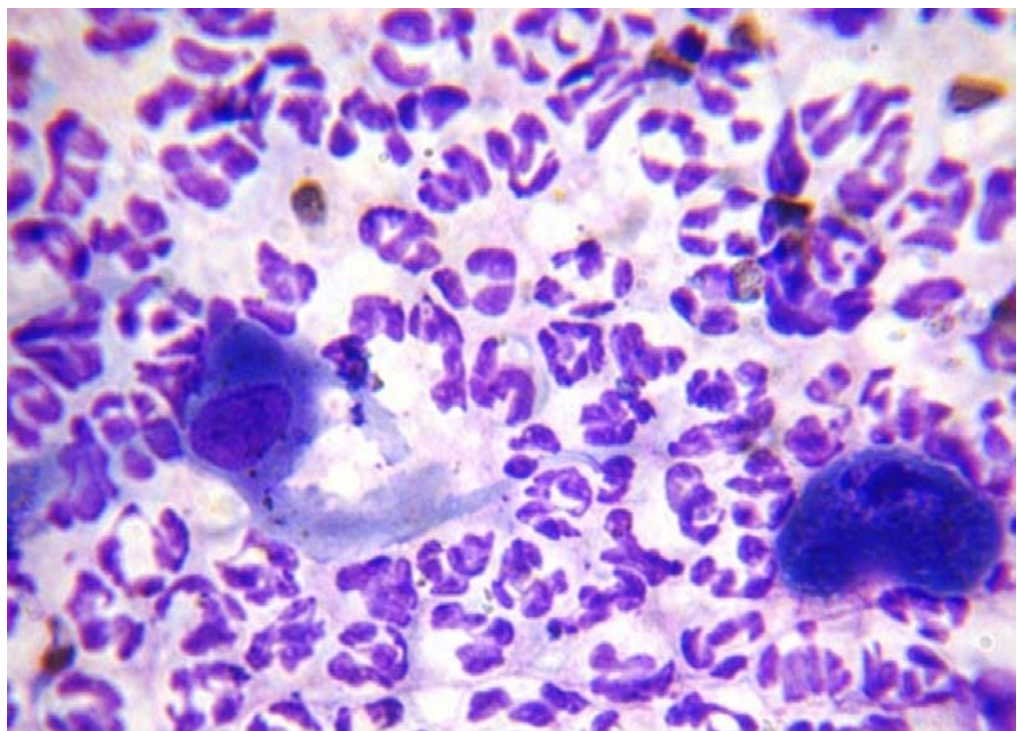

Figura 2. Intensa resposta neutrofílica com presença de bactérias cocoides em amostra de citologia cutânea de muar.

$\mathrm{Na}$ análise histopatológica das lesões (Fig. 3), a epiderme exibiu hiperplasia regular, ortoqueratose em trançado de cesto e compacta, além de focos de intensa exocitose de neutrófilos com formação de crostas na periferia de óstios foliculares (foliculite superficial). Não se evidenciaram sinais de acantólise. $\mathrm{Na}$ derme superficial, observou-se edema, congestão de vasos sanguíneos e infiltrado inflamatório misto em padrão perivascular com eosinófilos, neutrófilos, linfócitos e plasmócitos. Os folículos pilosos exibiram hiperqueratose infundibular leve, e não se evidenciaram parasitas foliculares. As glândulas sebáceas estavam discretamente hiperplásicas e as apócrinas, dilatadas. Ainda foi realizada coloração Periodic Acid-Schiff (PAS) para visualização de fungos, cujo resultado foi negativo.

No hemograma, observou-se discreta leucocitose por neutrofilia com desvio à esquerda, eosinofilia e monocitose. A contagem de eritrócitos e trombócitos e a dosagem de proteínas plasmáticas estavam dentro da normalidade. 
Para confirmação do diagnóstico, foi realizada a captura de mosquitos no local de origem, sendo estes acondicionados em álcool $70 \%$. A análise taxonômica identificou insetos da família Ceratopogonidae, gênero Culicoides spp.

Desta forma, foi indicada aplicação tópica de repelente de citronela ao redor das áreas afetadas e, sobre as lesões, pomada manipulada contendo dimetilsufóxido $(10 \%)$, sulfadiazina $(5 \%)$, ureia
(5\%) e vitamina A (150.000 UI), três vezes ao dia, durante 30 dias. A higienização do ambiente onde o animal habitava também foi orientada ao proprietário. Ao término do tratamento, o paciente apresentou remissão completa do quadro clínico e melhoria da condição física em geral (Fig. 4). Um novo hemograma foi solicitado e revelou normalidade de todos os parâmetros avaliados.
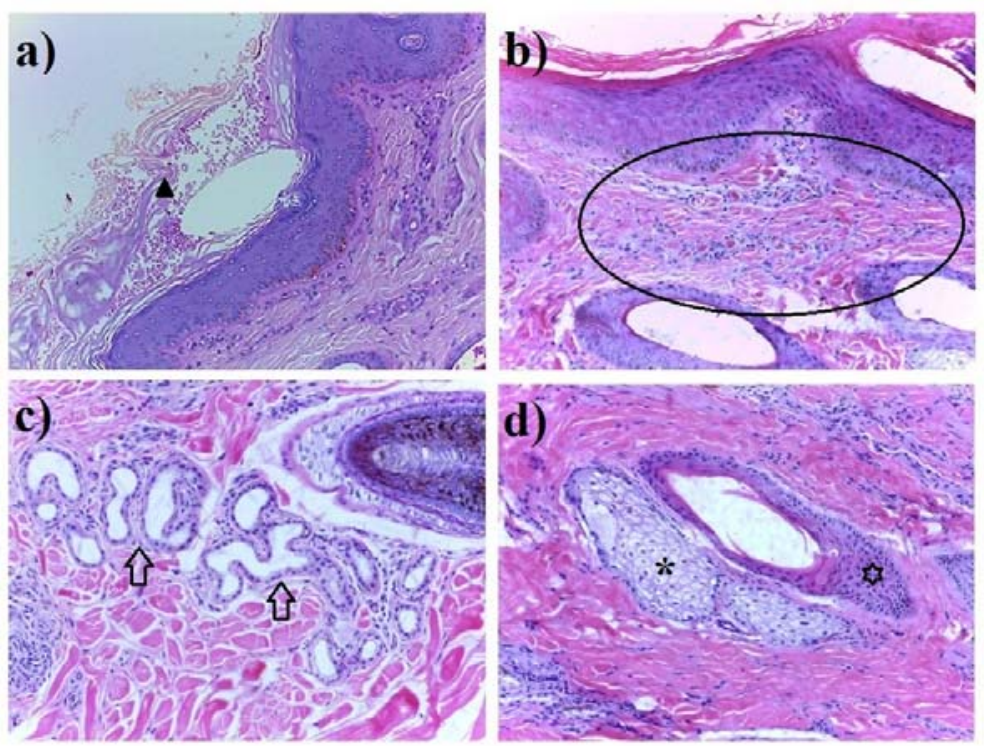

Figura 3. a) Formação de crosta na epiderme (cabeça de seta). b) Edema e congestão de vasos sanguíneos na derme superficial (círculo). c) Glândulas apócrinas dilatadas (setas vazias). d) Folículos pilosos exibindo hiperqueratose infundibular leve (estrela); ao lado, glândulas sebáceas discretamente hiperplásicas (asterisco).

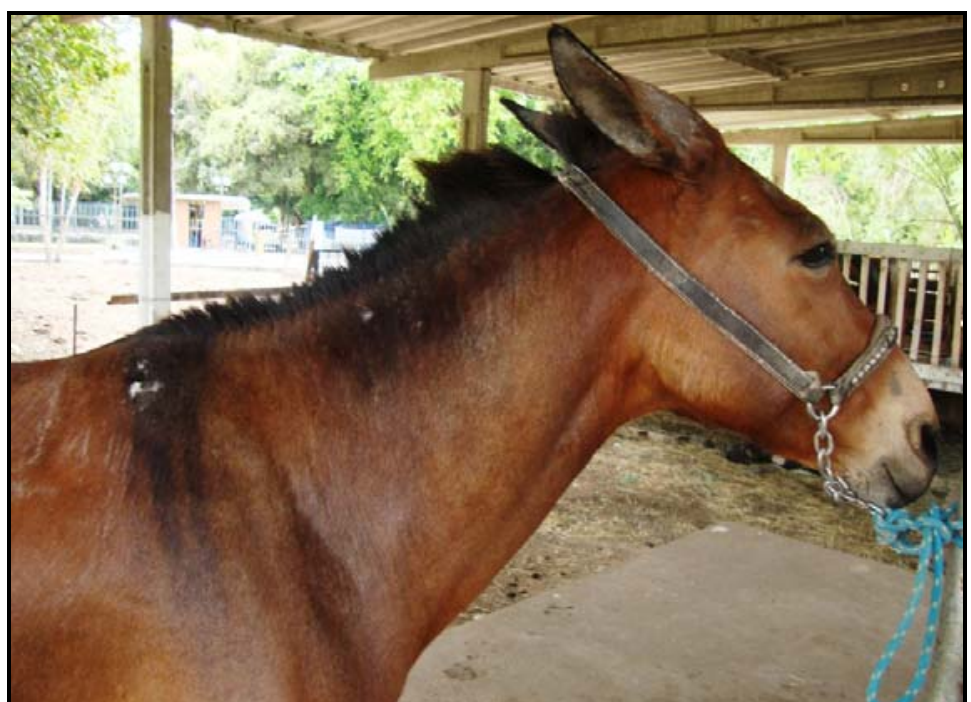

Figura 4. Muar em estado de convalescência após 21 dias em uso de terapia específica para dermatite alérgica. 


\section{DISCUSSÃO}

A DAPE é de ocorrência comum entre os animais domésticos, porém pouco diagnosticada na clínica de equídeos, por ser frequentemente confundida com outras enfermidades dermatológicas de origem bacteriana e fúngica, a exemplo da dermatofilose e dermatofitose. Diante disso, ressalta-se a importância de exames complementares no auxílio diagnóstico e nas indicações terapêuticas satisfatórias (Rees, 2005).

A dermatite superficial perivascular eosinofílica crônica observada na histopatologia, associada ao histórico, sinais clínicos e demais exames complementares, sugere uma dermatopatia alérgica à saliva de artrópodes com piodermite secundária (Hellberg et al., 2006). Contribui para esse diagnóstico a identificação de artrópodes parasitando os equídeos, tais como os Culicoides spp., que são dípteros hematófagos. No Brasil, são registradas mais de 75 espécies desses insetos (Yu, 2006).

A saliva desses parasitas é composta por proteínas, as quais atuam como alérgenos e poderão estimular a produção de IgE. Essas imunoglobulinas, por sua vez, interagem com mastócitos epiteliais, desencadeando sua degranulação, após segunda exposição com o alérgeno e consequente liberação de mediadores inflamatórios, tais como histamina, prostaglandinas e leucotrienos. A ação conjunta desses componentes resulta em quimiotaxia para neutrófilos e eosinófilos, edema e destruição tecidual, o que caracteriza uma resposta de hipersensibilidade do tipo I (Tizard, 2002) e leva ao aparecimento de lesões cutâneas, prurido intenso, dor e, até mesmo, automutilação (Anderson et al., 1988).

O tratamento sintomático é realizado com a utilização de anti-inflamatórios, antihistamínicos, antibacterianos, para o controle de infecções secundárias, e de substâncias tópicas que visem à reepitelização da pele lesionada (Robinson, 2009).

O dimetilsufóxido (DMSO) é um composto químico orgânico com mais de 30 propriedades farmacêuticas, que possui elevada penetração e difusão nas células. Por isso, há vários anos é incluído na medicina de equídeos como veículo para carrear e potencializar diversas soluções, por meio de membranas e tecidos. Como ação analgésica e anti-inflamatória, o DMSO pode ser usado como alternativa aos glicocorticoides por inibir a quimiotaxia de polimorfonucleares e neutralizar a atuação lesiva de radicais livres de oxigênio, o que previne a irritação local e a destruição tecidual (Robinson, 2009).

A sulfadiazina apresenta excelente atividade antibacteriana contra espécies de Streptococcus, entre outras bactérias, além de ter seu desempenho potencializado quando na presença de ureia. A ureia possui ainda ação umectante, a qual, da mesma forma que a vitamina $\mathrm{A}$, atua sobre o tecido epitelial e, consequentemente, auxilia na manutenção e regeneração dele (Rees, 2005).

Dessa forma, a associação tópica dos fármacos indicados, bem como as orientações técnicas acerca da higienização do ambiente em que o animal habitava, foi eficiente para o tratamento e, assim, permitiu completa remissão do quadro clínico em um intervalo de aproximadamente 30 dias.

\section{CONCLUSÕES}

Este trabalho relatou achados clínicos e patológicos da dermatite alérgica à picada de Culicoides spp. em muar, além de alertar sobre a importância de exames complementares para a realização do diagnóstico diferencial e o direcionamento terapêutico adequado.

\section{REFERÊNCIAS}

ANDERSON, G.S.; BELTON, P.; KLEIDER, N. The hypersensitivity of horses to Culicoides bites in British Columbia. Can. Vet. J., v.29, p.718723, 1988.

BROSTRÖN, H.; LARSSON, A.; TROEDSSON, M. Allergic dermatitis (sweet itch) of Icelandic horses in Sweden: an epidemiological study. Equine Vet. J., v.19, p.229-236, 1987.

CORRÊA, T.G.; FERREIRA, J.M.; RIETCORREA, G. et al. Seasonal allergic dermatitis in sheep in southern Brazil causaed by Culicoides insignis (Diptera: Ceratopogonidae). Vet. Parasitol., v.145, p.181-185, 2007. 
FADOK, V.A.; GREINER E.C. Equine insect hypersensitivity: skin test and biopsy results correlated with clinical data. Equine Vet. J., v.22, p.236-240, 1990.

FERREIRA, J.L.M. Dermatite alérgica sazonal. In: RIET-CORREA F.; SCHILD A.L.; LEMOS R.A.A.; BORGES J.R.J. (Eds.). Doenças de ruminantes e equinos. 3.ed. Santa Maria: Pallotti, 2007. v.2, p.624-626.

HELLBERG, W.; WILSON, A.D.; MELLOR, P. et al. Equine insect bite hypersensitivity: Immunoblot analysis of IgE and subclass responsis to Culicoides desnubeculosus salivary glan extract. Vet. Immunol. Immunopathol., v.113, p.99-112, 2006.

HENRY, A.; BORY, L. Dermatose estivale recidivante du cheval: pathology et therapeutique. Rec. Méd. Vét., v.113, p.65-78, 1937.
PORTUGAL, M.A.S.C.; GUERRA, J.L.; BALDASSI, L. et al. Dermatite estival recidivante em eqüinos. Arq. Inst. Biol., v.63, p.1-6, 1996.

REES, C.A. Diagnosing and managing equine pruritus: insect hypersensitivity. Compendium, v.27, 2005. Disponível em: $<$ http://www.vetfolio.com/dermatology/diagnosi ng-and-managing-equine-pruritus-insecthypersensitivity>. Acesso em: 14 set. 2017.

ROBINSON, N.E. Current therapy in equine medicine 6. 6.ed. St. Louis: Saunders, 2009. $1066 \mathrm{p}$.

TIZARD, I.R. Imunologia veterinária. 6.ed. São Paulo: Roca, 2002, 546p.

YU, A.A. Insect hipersensitivity. In: WHITE, S.D.; YU, A.A. Equine dermatology. In: ANNUAL CONVENTION OF THE AMERICAN ASSOCIATION OF EQUINE PRACTITIONERS, 52., 2006, Texas. Proceedings... Texas: AAEP, 2006. 